\title{
Axial, a zebrafish gene expressed along the developing body axis, shows altered expression in cyclops mutant embryos
}

\author{
U. Strähle, P. Blader, D. Henrique, ${ }^{1}$ and P.W. Ingham \\ Imperial Cancer Research Fund (ICRF), Developmental Biology Unit, Department of Zoology, ${ }^{1}$ Molecular Embryology \\ Laboratory and Developmental Genetics Laboratory, University of Oxford, Oxford, OX1 3PS UK
}

\begin{abstract}
Here, we report the cloning of a cDNA from zebrafish encoding a member of the fork head/HNF3 gene family. The gene, which we have called Axial, begins to be expressed just before gastrulation in a narrow region on the dorsal side of the embryo, the fish equivalent of the amphibian organizer. Expression can be detected in the involuted cells comprising the mesendoderm of the developing axis. At the end of gastrulation expression is turned on in the ventral neural plate in cells adjacent to the Axial-expressing mesodermal cells. Thus, Axial appears to be a target of both mesoderm induction and neural induction, leading to expression in cells of all three germ layers along the developing axis. Like the Brachyury gene, Axial is strongly induced by activin $A$, suggesting a role for endogenous activins in specifying the overlapping domains of expression of these two genes along the axis. Axial-expressing cells in the neuroectoderm include those of the future floor plate and cells of the ventral forebrain. In embryos homozygous for the cyclops mutation, expression is normal in mesendodermal cells but is absent from the ventral neural tube. The primary defects of cyclops mutants (lack of floor plate, deficiencies in the brain and cyclopia) correlate well with the expression domain of the Axial gene in wild-type neuroectoderm. The lack of Axial expression in cyclops neuroectoderm suggests that activation of Axial may be an immediate response of cyclops gene activity. Taken together, our data suggest that Axial plays a crucial role in specification of both the axial mesendoderm and the ventral central nervous system.
\end{abstract}

[Key Words: Zebrafish; Axial gene; mesoderm induction; floor plate; fork head domain; cyclops mutant embryos]

Received January 12, 1993; revised version accepted April 5, 1993.

The basic body plan of the vertebrate embryo is established by a series of embryonic inductions (Spemann 1938). In amphibians, signals from the vegetal hemisphere induce mesoderm in the marginal region of the embryo, and various growth factors or growth factor-like molecules have been shown to have such mesoderminducing activities (Slack et al. 1989; Green and Smith 1991; Jessel and Melton 1992). Recently, several genes have been cloned from Xenopus that are responsive to mesoderm-inducing signals (Rosa 1989; Cho et al. 1991; Smith et al. 1991; Dirksen and Jamrich 1992; Knöchel et al. 1992; Ruiz i Altaba and Jessel 1992; Taira et al. 1992). When mesoderm and ectoderm have become juxtaposed by the gastrulation movements, signals from the mesoderm lead to the induction and regionalization of the neuroectoderm (for review, see Slack and Tannahill 1992). A well-studied example of this secondary inductive event is that of the floor plate along the ventral midline of the neural tube by the underlying notochord. In the chicken, grafting notochord pieces laterally to the neural tube leads to the formation of a secondary floor plate (Placzek et al. 1991 and references therein).
Zebrafish embryos homozygous for the cyclops mutation, a recessive embryonic lethal mutation, do not form a floor plate and show fused eyes (Hatta et al. 1991). Cell transplantation experiments between wild-type and mutant embryos suggest that the cyclops mutation interferes with the reception of the signal emitted by the notochord. Wild-type cells transplanted into the neuroectoderm of cyclops mutants differentiate into floor plate cells and express floor plate-specific markers. Wild-type cells, however, transplanted into the notochord of mutant embryos do not rescue the floor plate (Hatta et al. 1991). The floor plate is believed to be involved in axon guidance in the neural tube (Bovolenta and Dodd 1991; Clarke et al. 1991; Placzek et al. 1991). In agreement, cyclops embryos are impaired in path-finding and fasciculation of axons in the spinal cord and the brain, an effect that can be mimicked by photo-ablating floor plate cells in wild-type embryos (Bernhardt et al. 1992; Hatta 1992). Ventral neurons in the anterior brain appear to be reduced in number by the mutation, whereas formation of primary and secondary motoneurons in the spinal cord appears to be unaffected (Hatta 1992). 
To obtain probes for the analysis of early patterning events in the zebrafish embryo, we have screened gastrula-stage RNA for the expression of conserved protein domains characteristic of certain families of regulatory molecules. We isolated a cDNA, named Axial, with high sequence similarity to the DNA-binding domain of the fork head/HNF3 gene family, a family of transcriptional regulators conserved from insects to mammals (Weigel et al. 1989; Lai et al. 1990, 1991; Weigel and Jäckle 1990; Häcker et al. 1992). Its expression in the fish organizer and its responsiveness to activin A suggests that it is involved in mesoderm specification in the fish embryo. In the early neurula, Axial expression is activated along the midline of the neural plate. Neural expression persists, whereas expression in the mesendoderm of the developing body axis is turned off during somitogenesis. Neural expression is absent in cyclops mutant zebrafish embryos, suggesting that Axial is a possible primary target for cyclops gene activity. Furthermore, it suggests that Axial plays a crucial role in the pathway that leads to specification of the ventral neuroectoderm ultimately giving rise to the floor plate and hypothalamus.

\section{Results}

Isolation of a fork head/HNF3-related cDNA from zebrafish gastrulae

To enrich for genes expressed during early stages of development, we prepared cDNA from total RNA isolated from zebrafish gastrula-stage embryos. Two degenerate oligonucleotide primers flanking the DNA-binding domain of the fork head/HNF3 gene family were designed to allow amplification by PCR (see Materials and methods). A 311-bp fragment with high sequence homology to the DNA-binding domain of the rat HNF3 $\beta$ gene (Lai et al. 1991) was isolated. This fragment was subsequently used as a probe to screen a cDNA library prepared from RNA isolated from embryos between the late gastrula and mid-somitogenesis stage $(8-15 \mathrm{hr}$ of development at $28.5^{\circ} \mathrm{C}$; for staging, see Westerfield 1989). Several independent phage were isolated.

The complete nucleotide sequence of the largest clone is shown in Figure 1A. This 1740-bp long cDNA contains a single long open reading frame of 409 amino acids that starts with a methionine preceded upstream by an inframe stop codon and a well-conserved Kozak sequence (Kozak 1986). An antisense RNA prepared from this clone recognizes a single RNA species of comparable size on Northern blots (see Fig. 3A, below), suggesting it to be close to full length.

Sequence comparisons with other members of the fork head/HNF3 gene family reveal a high degree of homology within the three conserved domains identified as being characteristic of family members (Weigel and Jäckle 1990; Lai et al. 1991). The first region (region I, amino acids 141-250, Figs. 1 and 2B), which is implicated in DNA binding (Lai et al. 1990 1991), is almost identical to that of the rat $H N F 3 \beta$ gene (Lai et al. 1991) with only three changes in the 109-amino-acid-long do-

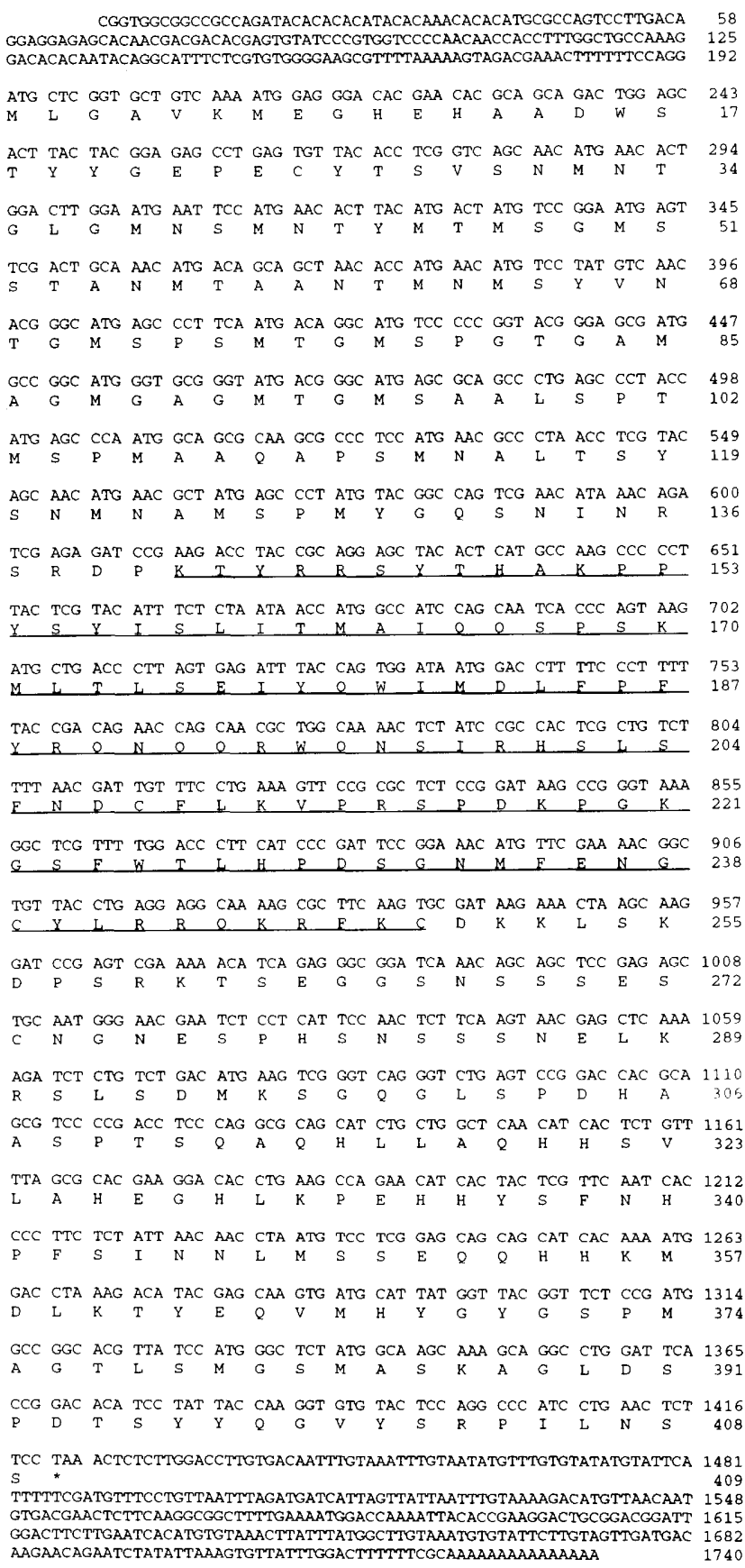

Figure 1. Nucleotide sequence of the Axial cDNA isolated from zebrafish. The predicted amino acid sequence is shown below the nucleotide sequence. Underlined is the highly conserved region I implicated in DNA-binding /Weigel and Jäckle 1990; Lai et al. 1990).

main. Lower sequence conservation is found in comparisons with the rat $H N F 3 \alpha$ (Lai et al. 1990), rat $H N F 3 \gamma$ (Lai et al. 1991), Xenopus XFKH1 (Dirksen and Jamrich 1992), XFD1/pintallavis (Knöchel et al. 1992; Ruiz i Altaba and Jessell 1992), rat BF1 (Tao and Lai 1992), and the fork head and fork head-related genes of Drosophila melanogaster (Weigel et al. 1989; Häcker et al. 1992). High degrees of sequence homology are also evident in the two 
Figure 2. Sequence comparison of the conserved region I of the fork head/HNF3 gene family. The following protein regions were aligned using the Geneworks alignment package (Intelligenetics): zebrafish Axial (ZF axl), amino acids 141-250; Drosophila melanogaster fork head (Dm fkh) amino acids 200-309 (Weigel et al. 1989|; rat HNF3 $\alpha$ amino acids 160-269 (Lai et al. 1990); rat HNF3 $\beta$ amino acids 149-258 (Lai et al. 1991); rat HNF3 $\gamma$, amino acids 77-186 (Lai et al. 1991); Xenopus laevis XFKH1 (X FKHl), amino acids 109-218 (Dirksen and Jamrich 1992); Xenopus laevis XFD1/pintallavis (X XFD1), amino acids 109-218 (Knöchel et al. 1992; Ruiz i Altaba and Jessel 1992); rat BF-1, amino acids 162-271 (Tao and Lai 1992).

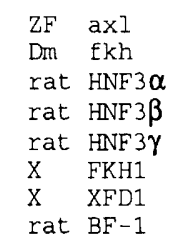

KTYRRSYTHAKP PYSYISLITMAIQQSPSKMLTLSEIYQWIMDLFPFYRQNQQRWQNSIR T- - FK- $-\mathrm{FK}-\mathrm{P}-\mathrm{P}-\mathrm{C}$ -G-D-PLA-1-1 -

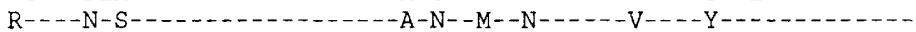
$\mathrm{R}-\cdots \mathrm{N}-\mathrm{S}-\ldots \ldots$ EGDKKNGKYE---F--NA--M---R---E-R---NG--EF--KN--Y--E-K-G-.-.-

$\begin{array}{ll}\mathrm{ZF} & \mathrm{axl} \\ \mathrm{Dm} & \mathrm{fkh} \\ \text { rat } & \mathrm{HNF} 3 \alpha \\ \text { rat } & \mathrm{HNF} 3 \beta \\ \text { rat } & \mathrm{HNF} 3 \gamma \\ \mathrm{X} & \mathrm{FKH1} \\ \mathrm{X} & \mathrm{XFD1} \\ \text { rat } & \mathrm{BF}-1\end{array}$

HSLSFNDCFLKVPRSPDK PGKGSFWTLHPDSGNMFENGCYLRRQKRFKCD -



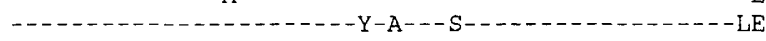

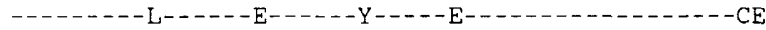

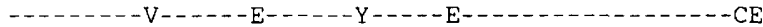
$-\mathrm{N}--\mathrm{L}-\mathrm{K}-\mathrm{V}-\mathrm{-}-\mathrm{NY}-\mathrm{D}---\mathrm{NY}-\mathrm{M}-\mathrm{H}-\mathrm{D}-\mathrm{DDV}-\mathrm{IG}-\mathrm{TT} T \mathrm{~K} L \mathrm{RR}-\mathrm{STTS}$ shorter conserved regions II and III ( Lai et al. 1991; Pani et al. 1992) in the carboxy-terminal part of the proteins (data not shown). Consistent with the homology scores in the strongly conserved regions I-III, the Axial and rat $H N F 3 \beta$ genes also show a high sequence similarity in the regions flanking these domains. The predicted Axial and $H N F 3 \beta$ proteins share $66 \%$ amino acid identity when short insertions are introduced to allow optimal alignment.

\section{Axial RNA is expressed most abundantly at the end of gastrulation}

The temporal pattern of Axial expression was analyzed by RNase protection (Sambrook et al. 1989). Uniformly ${ }^{32}$ P-labeled RNA probes synthesized in vitro from the Axial PCR fragment (for details, see Materials and methods,) were hybridized to equal amounts of total RNA from different embryonic stages, treated with RNases, and separated on a sequencing gel. Axial transcripts are detectable in RNA prepared from embryos at $\sim 50-70 \%$ epiboly, the stage at which gastrulation begins (Fig. 3B, lane 2). Transcripts could not be detected in RNA prepared from blastula-stage embryos (Fig. 3B, lane 1), suggesting that expression of Axial is exclusively zygotic. The amount of Axial transcript in total RNA increases toward the end of gastrulation, as neurulation commences at $90-100 \%$ epiboly (Fig. 3B, lane 3). In subsequent embryonic stages Axial RNA decreases in abundance but remains detectable even in RNA prepared from whole adult fish.

\section{Axial expression marks the dorsal side of the gastrula-stage embryo}

The spatial expression of Axial was analyzed by in situ hybridization of digoxygenin-labeled RNA probes to whole embryos. Transcripts are first detectable by this technique in embryos at $40 \%$ epiboly (Fig. 4A). At this stage, the expression domain forms a narrow band covering $\sim 10-20^{\circ}$ of the marginal circumference of the blas- toderm that marks the future dorsal side of the embryo. As gastrulation begins, the dorsoventral axis becomes morphologically apparent by the formation of a distinct thickening of the cell layers at the dorsal side of the embryo, the so-called embryonic shield. The Axial expression domain then begins to extend toward the animal pole; transcript is found exclusively in the newly forming hypoblast, the inner cell layer that gives rise to

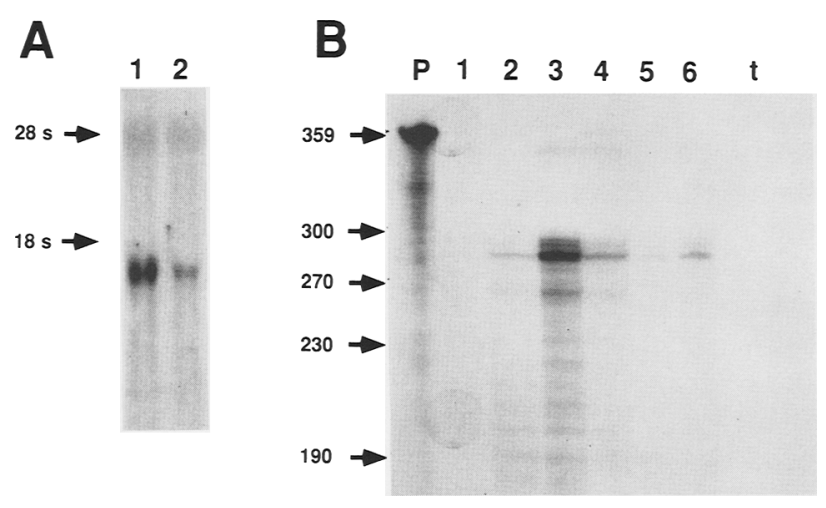

Figure 3. Expression analysis of Axial RNA in early embryonal-stages. (A) Autoradiograph of a Northern blot. Total RNA $(20 \mu \mathrm{g})$ isolated from 2-8 somite-stage embryos (lane 1) or from 14-18 somite-stage embryos (lane 2) was analyzed by Northern blotting with the Axial probe. The position of $18 \mathrm{~S}$ and $28 \mathrm{~S}$ rRNA are indicated by arrows. $(B)$ Autoradiograph of an RNase protection experiment. Total RNA $(5 \mu \mathrm{g})$ isolated from blastula (dome stage, lane 1), early gastrula (50-70\% epiboly, lane 2), late gastrula/early neurula (90-100\% epiboly, lane 3), 14 somite (lane 4), 26 somite (lane 5) and adult (lane 6) were hybridized to a 359-bp long uniformly labeled antisense RNA probe (see Materials and methods) and subjected to digestion with RNases. RNase-resistant fragments were separated on a sequencing gel, the autoradiograph of which is shown. Arrows indicate size markers. The protected fragment is slightly larger than expected (see Materials and methods). Control lanes: $(\mathrm{P})$ probe not treated with RNase; $(t)$ probe hybridized to $5 \mu \mathrm{g}$ of tRNA and then RNase treated. 


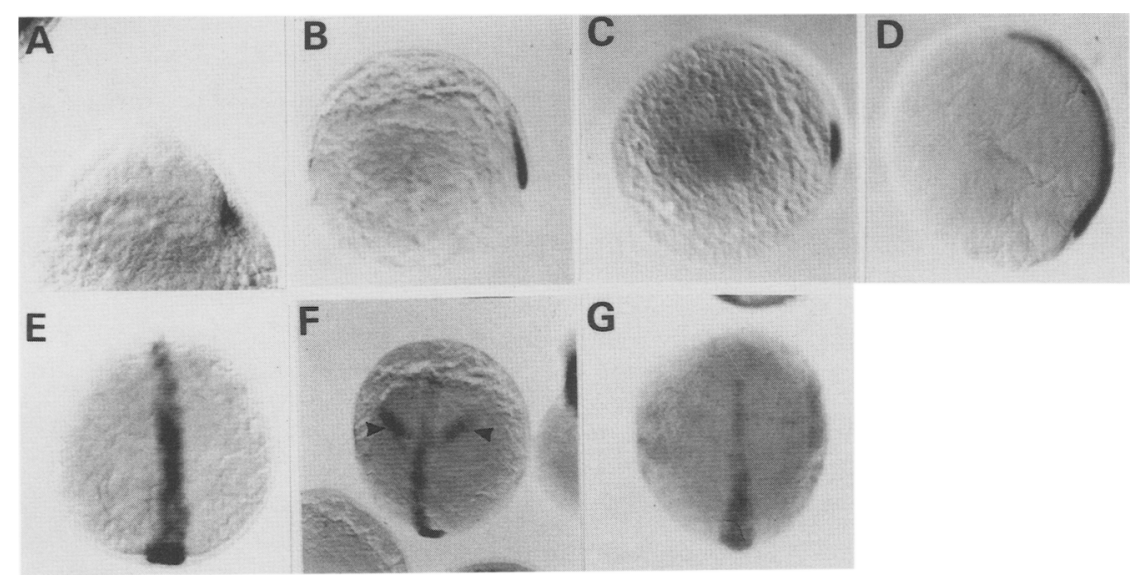

Figure 4. Axial is expressed in the forming axis along the dorsal side of gastrulastage embryos analysis of the spatial expression of the Axial gene by in situ hybridization of digoxigenin-labeled probes to whole embryos. Axial-expressing regions are stained by the alkaline phosphatase reaction product (see Materials and methods). (A) $40 \%$ epiboly-stage embryo (lateral view, anterior up); $(B) 60 \%$ epiboly-stage embryo (dorsal right, anterior up); (C) $60 \%$ epiboly-stage embryo (view from vegetal pole, dorsal side right); (D) $80 \%$ epiboly-stage embryo (lateral view, dorsal right, anterior upl; (E) $80 \%$ epiboly-stage embryo (dorsal view, anterior up). $(F, G)$ Embryos $(90 \%$ and $70 \%$ epiboly stage, respectively) labeled with the $\operatorname{pax}[Z F-b]$ and the Axial probe (dorsal views, anterior up). Arrowheads highlight the wing-like expression domains of the $Z F(p a x-b]$ in the mesencephalon anlage of the $90 \%$ epiboly-stage embryo on each side of the Axial expression domain. Embryos (70\% epiboly stage) show only Axial expression.

endodermal and mesodermal derivatives (Fig. 4B, lateral views; Fig. 4C, view from the vegetal pole onto the blastoderm margin). Sagittal optical sections through embryos at $60 \%$ epiboly show that the expression is restricted to the hypoblast layer and also indicate that the yolk syncytial layer does not express the gene (Fig. 5A).

As gastrulation continues, more cells are recruited into the dorsal midline and these cells also start to express Axial. Thus, by the $80 \%$ epiboly stage, a band of expressing cells extends along the dorsal side of the embryo from the blastoderm margin to the animal pole (Fig. 4D, lateral view; Fig. 4E, dorsal view). This band is slightly broader at the margin and becomes narrower toward the animal pole, reflecting the convergence and extension movements that give rise to the main body axis.

To map the anterior boundary of Axial expression, we hybridized gastrula-stage embryos with probes for Axial and $Z F[p a x-b]$. The latter gene is expressed in early neurulae in the primordium of the mesencephalon (Krauss et al. 1991a,c; Püschel et al. 1992a). At 90\% epiboly, transcripts from both genes are clearly detectable (Fig. $4 \mathrm{~F})$; in contrast at $70-80 \%$ epiboly, only Axial transcript is detectable (Fig. 4G). This shows that the anterior boundary of Axial expression in the late gastrula coincides with the diencephalon anlage on the neural plate. At the end of gastrulation when the giant yolk cell has been completely covered by cells, the Axial expression domain extends from the animal pole to the vegetal pole in a narrow stripe, $\sim 5$ cell diameters wide (data not shown).

\section{Axial and Brachyury expression domains overlap but are not identical in gastrula-stage embryos}

The early expression domain of the Axial gene at the dorsal side of the embryo coincides with a region in the fish embryo that has been shown to have properties similar to those of the amphibian organizer (Spemann 1938). Grafting this region (Luther 1935; Oppenheimer 1936;
Ho 1992) to the ventral side results in the induction of a secondary axis in the recipient embryo. In zebrafish, the Brachyury protein is expressed around the involuting margins of gastrulating embryos and in the axial mesoderm, marking the precursor cells of the future notochord. In neurula-stage embryos, Brachyury protein is detected exclusively in the notochord and tail bud. (Schulte-Merker et al. 1992). To map the expression of the Axial gene along the developing axis with respect to the Brachyury gene, we performed double-labeling experiments, restaining Axial antisense RNA-labeled embryos with the antibody directed against the zebrafish Brachyury protein (Schulte-Merker et al. 1992). Because the Brachyury protein localizes to the nucleus, it can easily be distinguished from cytoplasmic transcripts in doubly labeled specimens. To improve resolution, stained embryos were embedded in wax and sectioned. A sagittal section through the developing embryonic shield of a $50-60 \%$ epiboly-stage embryo in which involution of the cells at the margins has just begun is shown in Figure $5 \mathrm{~B}$. At the very blastoderm margin, cells express both Axial and Brachyury, however, Axial-positive cells, which are farther up in the hypoblast, having involuted slightly earlier, do not express the Brachyury protein. The Axial expression domain therefore also includes precursor cells that give rise to more anterior structures, such as the presumptive pharyngeal endoderm and prechordal plate mesoderm. Figure $5 \mathrm{C}$ shows a sagittal section of a $70-80 \%$ epiboly-stage embryo where the involution of the hypoblast layer of cells has progressed much further. The cells in the hypoblast along the posterior dorsal midline express both Axial and Brachyury. The width of the cell stripe expressing both genes is identical (Fig. 5D, data not shown). The anterior-most hypoblast cells, however, show only Axial expression. In $90 \%$ epiboly-stage embryos, the expression domain of the Brachyury protein ends anteriorly at the level of the $Z F[$ pax-b] expression domain, marking the mesenceph- 
Figure 5. Section of zebrafish embryos showing the distribution of Axial RNA (blue) and Brachyury protein (yellowish brown). (A) Embryo (60\% epiboly stage) loptical sagittal section, dorsal to the right, anterior up labeled with the Axial probe only (blue). The arrowhead points to yolk syncytial layer; asterisks mark the epiblast. $(B-F)$ Sections of specimens labeled with the Axial probe (blue) and the Brachyury antibody (yellowish brown, nuclear stain|. Note that in sections $C-F$ the yolk granules were lost during processing of the specimens. The position of the yolk is indicated $(\mathrm{Y})$. (B) Sagittal section through embryonic shield of a $50-60 \%$ epiboly-stage embryo (dorsal right, anterior $u p$ ). The arrowhead points to the yolk syncytial layer. The blastoderm margin is indicated by an asterisk. (C) Sagittal section through the embryonic shield of a $70 \%$ epiboly-stage embryo (anterior to the left, dorsal up). (D) Transverse section through the embryonic shield of a $90 \%$ epiboly-stage embryo (dorsal up). Cells in the neural plate begin to express Axial at this stage. The arrowhead indicates a cell that stains with the Axial probe but not with the Brachyury antibody. $(E)$ Sagittal section through 8 somite-stage embryo. Axial expression is mostly confined to the ventral neural keel (arrowhead) The notochord showing strong staining with the Brachyury antibody is indicated by an arrow. $(F)$ Sagittal section through the tail bud of a 12 somite-stage embryo. Arrowheads indicate cells above and below the differentiating notochord that express $A x$ ial but not Brachyury.
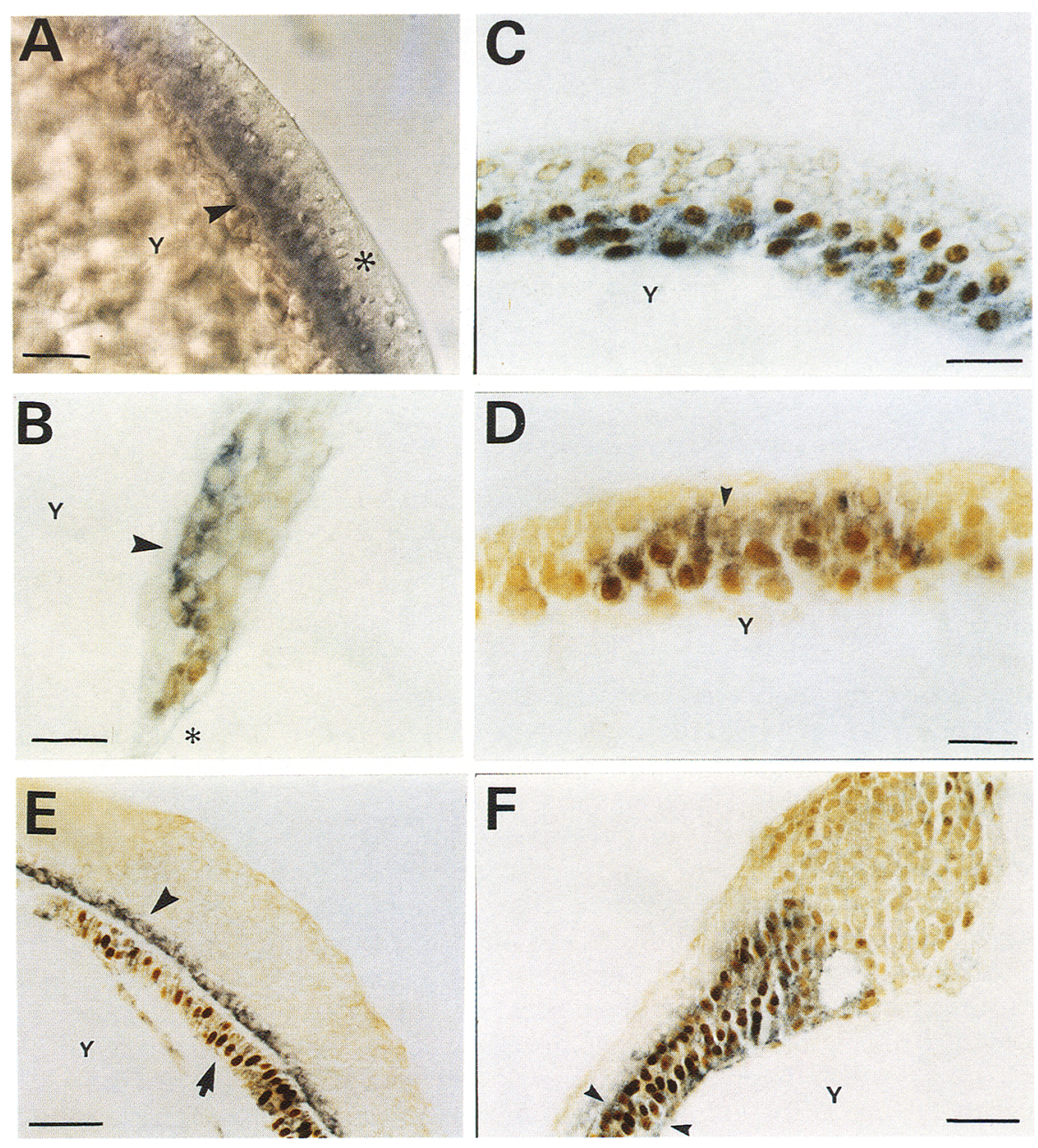

alon anlage; in contrast, Axial expression extends up to the animal pole /data not shown; for comparison with Axial expression, see Fig. 4F).

When gastrulation is almost completed ( $90 \%$ epiboly), Axial mRNA-positive cells that do not stain for the Brachyury protein become evident above the cells of the hypoblast expressing both genes (Fig. 5D, transverse section). Thus, with beginning neurulation Axial expression is initiated in the midline cells of the neural plate, suggesting that it is not only a target of mesoderm induction but also of neural induction. At the end of gastrulation, Axial is expressed in all three germ layers along the midline of the forming body axis.

\section{The Axial gene is strongly induced by activin $A$}

The mesoderm-inducing factor activin $\mathrm{A}$ is a potent inducer of the Brachyury gene, both in Xenopus (Smith et al. 1991) and zebrafish (Schulte-Merker et al. 1992). To assess whether Axial is similarly induced by activin A, blastoderm cells of 1000 cell-stage embryos were dissociated by incubation in $\mathrm{Ca}^{2+}$ - and $\mathrm{Mg}^{2+}$-free Ringer's solution (Westerfield 1989) and then cultured in the presence of Xenopus laevis activin A or in buffer alone. RNase protection analysis of treated cells revealed that Axial RNA is strongly induced by $10 \mathrm{U} / \mathrm{ml}$ of activin A (Fig. 6). Axial transcripts are also detectable at low levels in untreated control cells, demonstrating that low-level expression of Axial can occur in isolated cells.

\section{Axial expression is predominantly confined to the ventral neuroectoderm in somitogenesis-stage embryos}

In embryos at the 8-10 somite stage, Axial expression extends from the level of the eye primordia in the brain to the tail bud in a narrow band of cells (see Fig. 8A, below). Transcript levels appear more prominent in the anterior neural keel and the tail bud than in the trunk region, expression in the trunk being confined mainly to a narrow band of cells in the neuroectoderm. Thus by this stage, Axial expression has undergone a remarkable switch, now being confined predominantly to ectodermal rather than mesoendodermal tissues.

To determine the precise location of Axial-expressing 


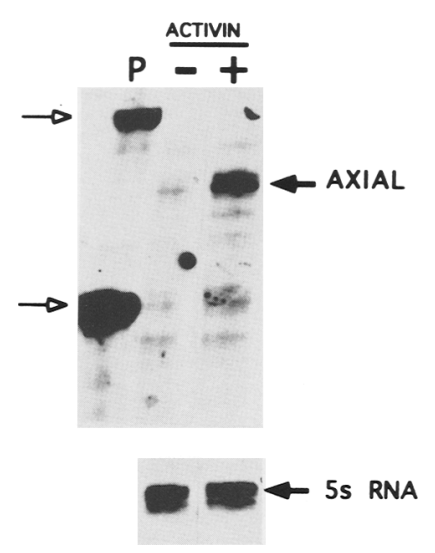

Figure 6. Zebrafish Axial is strongly induced by Xenopus activin A. RNase protection analysis of RNA isolated from dissociated blastoderm cells cultured in the presence $(+)$ or absence $1-1$ of $10 \mathrm{U} / \mathrm{ml}$ of Xenopus activin A. Uniformly ${ }^{32} \mathrm{P}$-labeled RNA probes synthesized from the Axial and 5S RNA cDNA /see Materials and methods) were hybridized to the RNA prepared from dissociated cells. The protected Axial RNA fragment is indicated by the upper solid arrow. To control for equal recovery and processing, RNA was hybridized to an antisense probe complementary to the zebrafish 5S RNA in addition to the Axial probe (bottom insert, lower solid arrow 5S RNA). Each lane corresponds to 50 dissociated blastoderm embryos. (P) Probes untreated. (Upper open arrow) Axial probe; (lower open arrow) 5S RNA probe.

cells in the 8-10 somite-stage embryo, the transcript distribution was analyzed in sectioned material (Fig. 7). In contrast to earlier stages, when expression is confined to the hypoblast, Axial transcript is found in the developing neural tube, a derivative of the epiblast layer. A region several cell layers thick at the ventral side of the developing brain expresses Axial at this stage (Fig. 7B). The expression domain in the neural keel becomes restricted more caudally to a stripe two to three cells wide and only one cell thick, which extends all along the body axis into the tail bud (Fig. 7C,D). Expression in the prechordal plate mesoderm, the differentiating notochord, and the underlying endoderm is only weakly detectable in these stages. We find, however, a patch of cells beneath the anterior tip of the notochord that shows staining also at the 10-somite stage (data not shown).

To map the anterior boundaries of the Axial expression domain more precisely, we performed double labeling using both the Axial probe and a second probe specific for either the Krox-20 gene (Oxtoby and Jowett 1993 ) or the zebrafish pax [ZF-a] gene (Krauss et al. 1991a). Both of the latter have well-defined expression domains in the primitive brain of an 8-somite embryo and thus serve as unambiguous markers of anatomical regions. Krox-20 is expressed in rhombomeres 3 and 5 in the hindbrain (Nieto et al. 1991; Oxtoby and Jowett 1993), whereas pax [ZF-a] is expressed in the thalamic region of the diencephalon, the hindbrain, and the spinal chord and weakly in the eye primordia of an 8- to 10somite embryo (Krauss et al. 1991b,c; Püschel et al. 1992b). The results of the double-labeling experiments are shown in Figure 8, B and C. Axial is expressed in a single cell layer in the hindbrain, which gradually becomes thicker in regions more anterior to rhombomere 3 (Fig. 8B). In the diencephalon, the Axial expression domain includes the ventral parts of the future hypothalamus but is separated dorsally from that of pax [ZF-a] expression by a narrow stripe of cells that express neither gene. The anterior boundaries of the two genes coincide (Fig. 8C).

In embryos at the same stage, Axial is also expressed at high levels in the center of the tail bud (Figs. 5E and 9G). This expression is modified more anteriorly (Fig. $5 \mathrm{~F}$ ). The developing notochord shows reduced staining but narrow bands of expressing cells persist both ventral and dorsal to the notochord. The dorsal band of expressing cells is continuous with the expression in the neural keel, whereas expression in cells ventral to the notochord is vanishing more anteriorly (Figs. 5E,F and Fig. 9G). As shown in Figure 5F, the core of the tailbud is formed by cells expressing both the Axial and the Brachyury gene. Cells expressing only Brachyury are also visible. The expression of the Axial gene in the tail

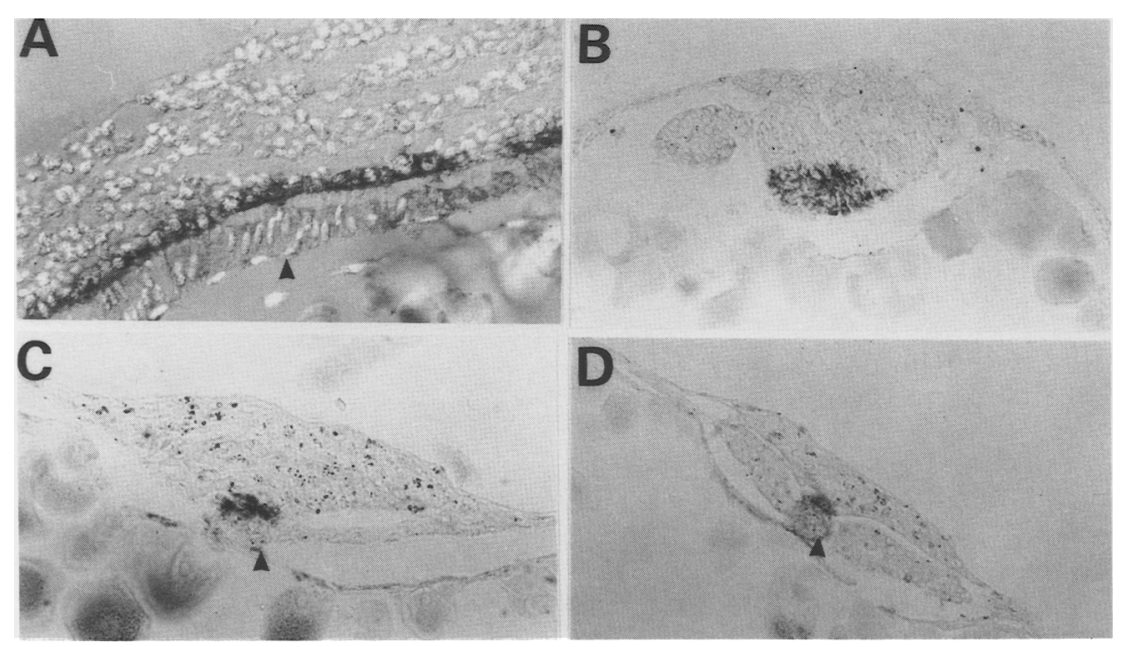

Figure 7. Sections through zebrafish embryos stained with the Axial probe. (A) Sagittal section through the hindbrain/anterior spinal cord region of an 8-10 somite-stage embryo. (B) Transverse section /slightly oblique) through the diencephalon. $(C)$ Transverse section through the posterior hindbrain. (D) Transverse section through the posterior spinal chord. The notochord is indicated by arrowheads. 


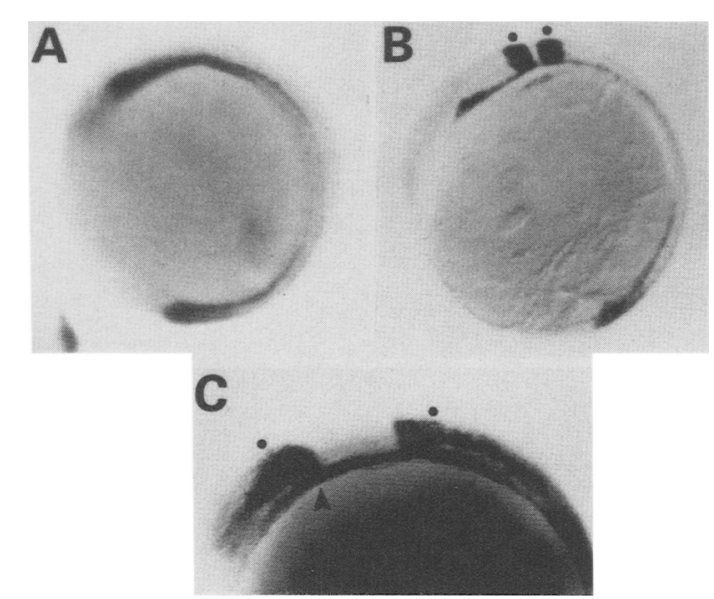

Figure 8. Expression of Axial is found predominantly in the ventral neural tube in somitogenesis-stage embryos. (A) An 8 somite-stage embryo stained with the Axial RNA probe. (B) Same stage embryo as in $A$ labeled simultaneously with the Krox-20 and the Axial probe. Expression of Krox-20 in rhombomeres 3 and 5 is indicated by dots. $(C) 8$ somite-stage embryo labeled with the Axial and the pax[ZF-a] antisense RNA probes. Dots indicate the expression of the $Z F[$ pax-a] gene in the diencephalon and the hindbrain/spinal chord. The expression domain of Axial is indicated by an arrowhead.

bud of an 8 somite-stage embryo appears to be reminiscent of the switch in expressing germ layers in the trunk region. The central cells of the tail-bud seem to have the same differentiation status as the precursor cells in the notochord primordium of an early gastrula-stage embryo.

\section{Neural expression of Axial is absent in cyclops mutant embryos}

cyclops is a recessive lethal mutation in which specification of the floor plate is impaired and the eyes are partially fused (Hatta et al. 1991). The effect of the cyclops mutation on Axial expression was analyzed by hybridizing 8 somite-stage embryos derived from cyclops heterozygous parents with the Axial RNA probe. Cyclopia can unambiguously be detected at these stages of development, allowing identification of homozygous mutant embryos. As shown in Figure 9, A and B, Axial is not expressed in the floor plate and the ventral parts of the brain of cyclops homozygotes. For comparison, a wild-type sibling processed in the same experiment is shown in Figure 9A. Expression in the center of the tail bud and the vanishing band of expressing cells below the notochord in the tail bud are not affected by the mutation. We performed double-labeling experiments using the $\operatorname{pax}[Z F-a]$ probe as an internal control for hybridization and staining efficiency. The results are shown in Figure 9,C and D. The narrow band of Axial expression between the two prominent pax[ZF-a] domains in the hindbrain and the diencephalon can be detected in wild type (Fig. 9C) but not in cyclops embryos (Fig. 9D) stained with the $\operatorname{pax}[Z F-a]$ probe to a similar degree as the wild-type control. In cyclops embryos, the Axial gene is not expressed in the ventral regions of the neural tube as shown in the sagittal sections through the anterior brain (Fig. 9E,F) and the tail bud (Fig. 9G,H). Axial expression can be detected, however, in the center of the tail bud of the 8-somite cyclops embryo at a level similar to that of wild-type, indicating that the mesendodermal
Figure 9. The Axial gene is not expressed in the ventral neural tube in embryos homozygous for the cyclops mutation. Eight somite-stage embryos were stained with the Axial probe shown as whole mounts or sections cut from labeled embryos. $(A, B) 8$ somite-stage wild-type $(A)$ and cyclops mutant $(B)$ embryos (anterior up, dorsal to the right $)$. $(C, D)$ Wild-type $(C)$ and cyclops mutant $(D)$ embryos stained in addition to the Axial probe with the pax $[Z F-a]$ probe (anterior up, dorsal view). The arrowhead in $C$ indicates Axial expression missing in cyclops embryos $(D)$ but visible between the two expression domains of ZF[pax-a] in the diencephalon and the hindbrain in wild-type embryos $(C)$. $(E, F)$ Sagittal sections (anterior to the right, dorsal up/ through the anterior brain of wild-type $(E)$ and cyclops mutant embryos $\langle F\rangle . \mid G, H)$ Sagittal sections (anterior right, dorsal up) through the tail bud of wild-type $(G)$ and cyclops $(H)$ embryos. The arrowhead indicates expression of Axial in the ventral neuroectoderm missing in cyclops $\mathrm{mu}$ tants.

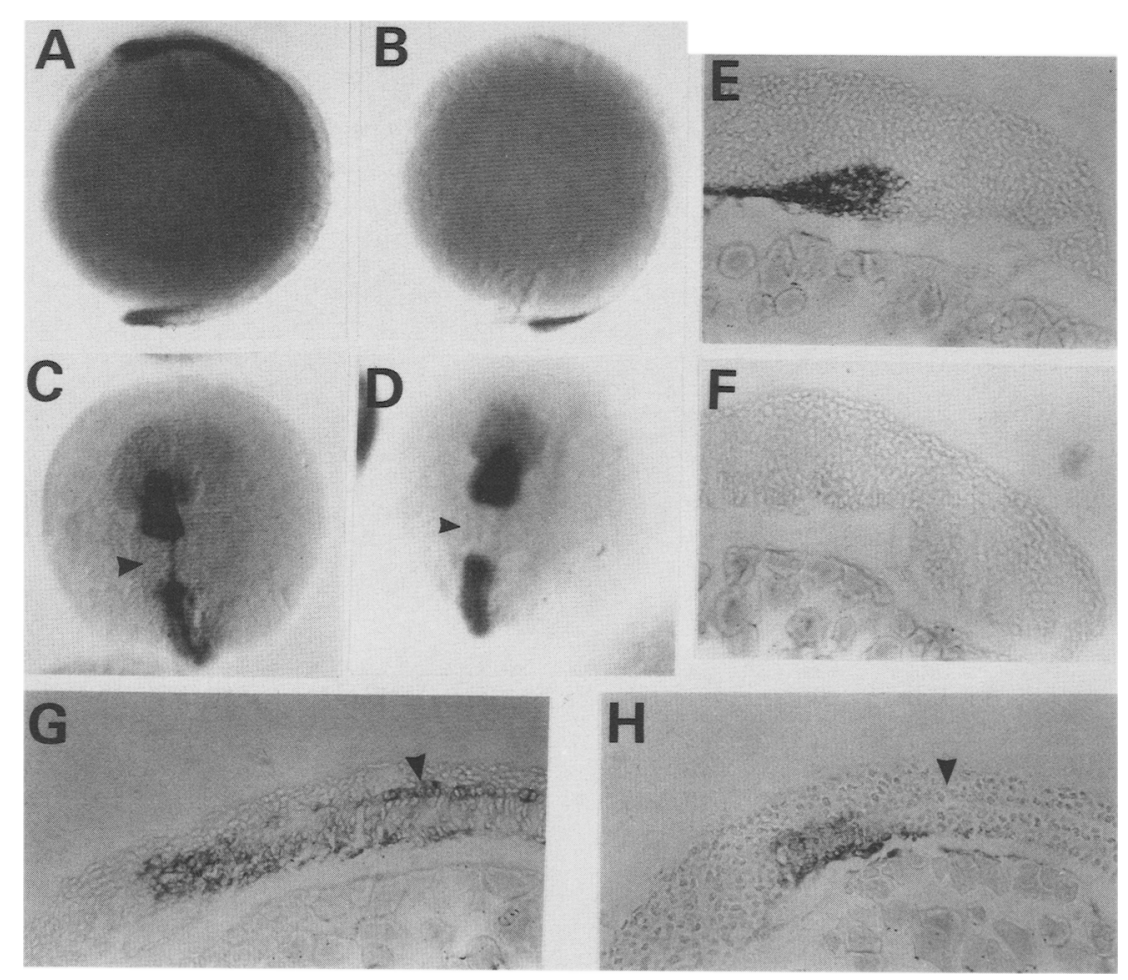


expression of the Axial gene is not affected by the $c y$ clops mutation. The expression of the pax [ZF-a] gene is unchanged by the cyclops mutation, supporting the notion that the defects in cyclops embryos are confined to the ventral aspects of the neural tube.

\section{Discussion}

Axial is a member of the fork head/HNF3 gene family

Sequence comparison of the Axial gene reveals it to be a member of the fork head/HNF3 gene family, distinct from those recently cloned from $X$. laevis (Dirksen and Jamrich 1992; Knöchel et al. 1992; Ruiz i Altaba and Jessel 1992). The zebrafish gene is related much more closely to the rat HNF3 $\beta$ gene $166 \%$ identical amino acids) than to the Xenopus genes $142 \%$ identical amino acids). In the adult rat, HNF3 $\beta$ is expressed in the liver and other endodermal derivatives (Lai et al. 1991). Zebrafish Axial and Xenopus XFKH1 and XFDl/pintallavis show very similar expression patterns in gastrula stages of their respective organisms, but they diverge somewhat as development proceeds. In contrast to the Xenopus genes, Axial expression is down-regulated in the developing notochord but remains expressed in the ventral neural tube at least until the end of somitogenesis. In addition, Axial expression can be detected in RNA prepared from adult fish, whereas expression of the $X f k h 1$ (XFD1') and XFD1 (pintallavis) genes ceases during neurulation of Xenopus. Knöchel et al. (1992) have reported high identity between the rat HNF3 $\beta$ region 1 and another Xenopus cDNA cXFD-3 isolated from a gastrula library, which may well be the true Xenopus ortholog of Axial. Given that we find expression of the Axial gene in adult zebrafish liver and gut (U. Strähle, unpubl.) it is likely that Axial is the zebrafish ortholog of the rat HNF3 $\beta$ gene.

\section{Expression of Axial marks the fish organizing center}

The dorsal side of the zebrafish embryo can first be distinguished during gastrulation with the formation of the embryonic shield, the cell mass from which the future body axis is derived. The results of grafting experiments (Luther 1935; Oppenheimer 1936; Ho 1992) suggest a functional equivalence of this region with the amphibian organizing center (Spemann and Mangold 1924). Expression of Axial becomes apparent at the dorsal margin of the blastoderm before the onset of gastrulation, expressing cells being the first to involute as gastrulation begins. In Xenopus, the vegetal half of the embryo sends out signals as early as the 32 -cell stage inducing the formation of the organizer (Nieuwkoop 1973; Gimlich and Gerhardt 1984; Smith et al. 1989). These processes are currently poorly understood in fish (Ho 1992), although grafting experiments in trout (Long 1983) suggest that the yolk syncytial layer of fish embryos has inducing properties similar to those of the vegetal hemisphere of amphibians. Moreover, our finding that Axial, like the zebrafish Brachyury (Schulte-Merker et al. 1992) gene, can be induced by Xenopus activin A provides strong evidence that the mesoderm-inducing mechanism is very similar between the two organisms.

The expression domains of Brachyury and Axial overlap but are not identical. In gastrula-stages, Brachyury is expressed in mesodermal cells around the entire blastoderm margin (the germ ring) and the mesendodermal cells of the dorsal midline (Schulte-Merker et al. 1992) extending up to the level of the mesencephalon anlage as revealed by comparison with the expression domain of pax/ZF-b] (U. Strähle unpubl.). In contrast, Axial expression is found only along the dorsal midline and extends further anteriorly; in addition, it is induced in the neuroectoderm overlying the mesoderm at the end of gastrulation. The width of the two expression domains is identical along the midline, suggesting that the same positional cues determine the lateral extent of the mesendodermal cells expressing the two genes. Axial and Brachyury respond to exogenously added activin A, indicating that activin or activin-like molecules could be involved in the overlapping expression domains of these two genes in the fish organizer. Axial-expressing cells are the first cells to involute during gastrulation, giving rise to prechordal plate mesoderm and pharyngeal endoderm. This is reminiscent of the Xenopus goosecoid gene (Cho et al. 1991). In contrast to goosecoid, however, $A x$ ial-expressing cells extend all along the axis and do not just include the presumptive prechordal plate cells.

Axial is redeployed in a neural organizing center, the ventral neuroectoderm

At the end of gastrulation, expression of Axial is induced in the neuroectoderm directly overlying the mesendoderm in which it is initially expressed, a phenomenon reminiscent of the postulated homeogenetic induction of Hox genes between germ layers (DeRobertis et al. 1989; Frohman et al. 1990). Axial expression is confined to the innermost cells of the neural plate immediately above the notochord. These cells are destined to form the ventral midline of the neural keel. In contrast to other vertebrates, neural tube formation in teleosts is achieved by the formation of a solid neural keel and not by folding of the neural plate. The central canal forms secondarily and is not lined with cells derived from the outermost layers of the neuroectoderm (Calberla 1877). The ventral part of the neural keel gives rise to the floor plate, which has an important role in axon guidance (Placzek et al. 1991; Bernhardt et al. 1992; Hatta 1992). Axial is expressed in the ventral neural keel from the diencephalon anlage along the whole body axis. The floor plate forms only from a subset of the cells expressing Axial. In the mesencephalon it consists of a stripe several cells wide, but this narrows to a one-cell-wide band in the posterior spinal cord (Kingsbury 1931; Hatta et al. 1991). Our data show that the neuroectoderm becomes specified to express Axial along its entire length before formation of the neural keel. The diversification of the neural plate occurs concurrently along both its dorsoventral and anteroposterior axes as shown by the simultaneous activation of the $Z F[p a x-b]$ and Axial genes toward the end of gastrulation. 
The Axial expression pattern in the tail bud in midsomitogenesis resembles that of a gastrula embryo

Expression of Axial is attenuated in the axial mesendoderm during somitogenesis. In an 8 somite-stage embryo, only relatively low levels of transcript remain detectable in the notochord and underlying axial endoderm, whereas strong expression persists in the center of the tail bud and the ventral neural keel. The cells in the center of the tail bud express both Axial and Brachyury, a state similar to that of cells along the trunk region of the earlier gastrula-stage embryo. A few cells more anteriorly, however, expression of Axial is turned down in the differentiating notochord. Some expression continues in the presumptive tail bud endoderm below the notochord for a short distance rostrad, and, in addition, expression is induced in the ventral neural plate, continuous with the expression in the neural tube of the trunk region. This suggests that processes such as mesoderm and neural induction characteristic of the regional specification of the head and the trunk regions during gastrulation are still in operation at later stages of development in the formation of the tail.

\section{Expression of Axial in the ventral neuroectoderm requires the cyclops gene}

Embryos homozygous for the cyclops mutation show impaired formation of the floor plate, disturbed axon guidance, cyclopia, and fusion of ventrolateral axon tracts and nuclei in the ventral brain (Hatta et al. 1991; Bernhardt et al. 1992; Hatta 1992). Hatta et al. (1991) have shown by cell transplantation that the floor plate defect in this mutation is the result of impaired reception of a floor plate-inducing signal by the ventral neural cells. Transplantation of wild-type cells into a mutant ventral neural tube results in differentiation of the transplanted wild-type cells into floor plate cells (Hatta et al. 1991). The expression domain of Axial in the neural keel shows a close correlation with the defects in cyclops mutants. The neural expression of Axial is absent in $c y$ clops mutant embryos; however, mesendodermal expression is unaffected in mutants.

The more pronounced defects in the brain of cyclops mutants seem to be the lack of ventral parts of the anterior neural keel resulting in fusion of the eyes and ventrolateral axon tracts and nuclei (Hatta et al. 1991; Hatta 1992). This is reminiscent of experimentally induced cyclopia caused by excision of medial parts of the rostral neural plate in amphibians and fish (Mangold 1931). As there is no evidence for cell death, the deficiencies in the cyclops brain are most likely the result of impaired cell proliferation (Hatta et al. 1991). The expression of $Z f$ [pax-a] in the more dorsal aspects of the central nervous system is undisturbed by the cyclops mutation in agreement with the notion that the defects in cyclops are confined to the ventral neural keel. The defects in the cyclops brain agree well with the anteriorly broadened and thickened expression domain of Axial in wild-type embryos. Taken together, these data suggest that the pleiotropic effects such as cyclopia, fusion of nuclei in the ventral brain, and lack of the floor plate are the result of a common cause, the improper specification of the ventral neural keel, which is reflected in the absence of Axial expression in the neuroectoderm of cyclops mutants.

The dependence of Axial expression in the neuroectoderm on cyclops activity suggests that Axial may act in the same signaling pathway, but downstream of the $c y$ clops gene. Its early induction in the differentiating neural plate and the lack of expression in cyclops embryos make Axial a likely candidate for a primary mediator of cyclops activity involved in specification of the ventral midline of the central nervous system.

\section{Materials and methods}

Fish stocks

Fish were grown and raised as described (Westerfield 1989). Mutant line cyclops cyc-1 (b16) and inbred wild-type fish were gifts from M. Westerfield, C. Kimmel, and K. Hatta /University of Oregon, Eugene). Staging of the embryos was carried out according to Westerfield (1989).

\section{Cloning of the Axial gene}

Total RNA was prepared according to the protocol of Chirgwin et al. (1979). RNA was reverse transcribed by use of DNA hexamers ( 10 pmoles/ $\mu \mathrm{g}$ of $\mathrm{cDNA}$ ) and $\mathrm{MLV}$ reverse transcriptase (Sambrook et al. 1989). Aliquots $(1 \mu \mathrm{g})$ of the cDNA were PCRamplified at $92^{\circ} \mathrm{C}$ for $1 \mathrm{~min}, 37^{\circ} \mathrm{C}$ for $1 \mathrm{~min}$, and $72^{\circ} \mathrm{C}$ for $1 \mathrm{~min}$ for 40 cycles (Kawasaki and Wang 1989). The primers employed were CGATGCGAATTCTACCCICACGCIAAGCCNCCNTA and CATGACTCTAGACTTCTCGTCCTTG/AAANCGC/ TTTC/TTG flanking the consensus sequence of the DNA-binding domains of the fork head/HNF3 gene family (Weigel and Jäckle 1990; Lai et al. 1991).

For construction of a cDNA library, total RNA from late gastrula $\left(8 \mathrm{hr}\right.$ at $\left.28.5^{\circ} \mathrm{C}\right)$ to mid-somitogenesis $\left(16 \mathrm{hr}\right.$ at $\left.28.5^{\circ} \mathrm{C}\right)$ embryos was isolated as described above. Poly $(\mathrm{A})^{+}$RNA was prepared using oligo(dT)-Sepharose (Sambrook et al. 1989). cDNA was prepared with a commercially available cDNA synthesis kit (Pharmacia), and the resulting cDNAs were cloned into the $\lambda$ ZAP II vector (Stratagene) following the instructions of the suppliers. Screening with the uniformly ${ }^{32}$ P-labeled RNA probe synthesized from the PCR fragment was carried out as described (Sambrook et al. 1989). The cDNAs were subcloned into the NotI site of Bluescript II (Stratagene). Subcloning and sequencing were performed following standard procedures (Sambrook et al. 1989).

\section{Northern blot analysis and RNase protection assays}

Aliquots of total RNA ( $20 \mu \mathrm{g})$ were separated on formaldehydeagarose gels, blotted onto Biodyne B membrane (Pall), and hybridized with a ${ }^{32} \mathrm{P}$-labeled antisense RNA probe synthesized from the full-length cDNA as described (Sambrook et al. 1989). The blot was exposed to a Kodak X-ray film for 8 days in the presence of an intensifying screen.

RNase protection analyzis of Axial expression was carried out as described previously (Strähle et al. 1987). A ${ }^{32}$ P-labeled antisense RNA probe was synthesized from the PCR fragment and hybridized to $5-\mu \mathrm{g}$ aliquots of total RNA. The resulting protected fragment ( $\sim 285$ nucleotides) was slightly larger than expected ( 272 nucleotides) as a result of incomplete RNase digestion at the ends of the protected fragment because these are formed by the degenerate primers used to amplify the Axial region $\mathrm{I}$. 
Whole-mount in situ hybridization and immunocytochemistry

Embryos were fixed in their chorions in BT-fix $14 \%$ paraformaldehyde, $4 \%$ sucrose, $0.12 \mathrm{mM} \mathrm{CaCl}_{2}, 0.1 \mathrm{M} \mathrm{NaPi}$ at $\mathrm{pH} 7.4$ ) at $4^{\circ} \mathrm{C}$ overnight. In situ hybridization was carried out by a modification of Tautz and Pfeifle (1989); dechorionated embryos were treated as for antibody staining (Westerfield 1989), except washings were carried out in PBT $(1 \times$ PBS, $0.1 \%$ Tween 20 , $0.2 \%$ BSA). Embryos were transferred to hybridization mix (HYB: $50 \%$ formamide, $5 \times \mathrm{SSC}, 50 \mu \mathrm{g} / \mathrm{ml}$ of heparin, $5 \mathrm{~mm}$ EDTA, $1 \mathrm{mg} / \mathrm{ml} \mathrm{rRNA}, 0.1 \%$ Tween 20 ) and prehybridized for $3-16 \mathrm{hr}$ at $55^{\circ} \mathrm{C}$. The buffer was replaced by fresh HYB containing $\sim 0.1 \mathrm{mg} / \mathrm{ml}$ of digoxygenin-labeled antisense RNA probe (Boehringer) and incubated at $55^{\circ} \mathrm{C}$ for $12-16 \mathrm{hr}$. Embryos were washed twice with $\mathrm{HYB}$, once at room temperature for 2 min and then at $55^{\circ} \mathrm{C}$ for $1 \mathrm{hr}$, followed by one wash in $50 \% \mathrm{PBT} /$ $\mathrm{HYB}$ at $55^{\circ} \mathrm{C}$ for $1 \mathrm{hr}$. Embryos were preabsorbed by washing twice with PBT before incubation in 1:2000 diluted anti-digoxygenein antibody (Boehringer) at $4^{\circ} \mathrm{C}$ overnight. DIG antibody had been preabsorbed in a $1: 200$ dilution to embryos. After five washes in PBT, bound antibody was detected by the alkaline phosphatase-staining reaction, and embryos were cleared in 1,2,3,4-tetrahydronaphthalene. Staining with the antiBrachyury antibody was carried out as described (SchulteMerker et al. 1992). Embryos were embedded for sectioning in wax as described (Godsave et al. 1988), and 8- $\mu \mathrm{m}$ sections were cut on a standard microtome.

\section{Activin induction}

Dechorionated embryos of the 1000-cell stage were dissociated into single cells by incubation in $\mathrm{Ca}^{2+}$ - and $\mathrm{Mg}^{2+}$-free Ringer's (Westerfield 1989), supplemented with either $5 \mu \mathrm{g} / \mathrm{ml}$ of BSA alone or together with $X$. laevis activin A. To speed up dissociation and to prevent reassociation, embryos were gently sucked up and down in a Pasteur pipette until a single cell suspension was gained. This procedure was repeated every $60 \mathrm{~min}$ to prevent reassociation of the cells. The cell suspension was kept at $28.5^{\circ} \mathrm{C}$ until control embryos had reached the end of gastrulation. RNA was prepared by lysis in $\mathrm{LiCl} /$ urea (Mohun et al. 1984 ) and analyzed by RNase protection. RNA was simultaneously hybridized to the Axial probe and a probe complementary to the 5S RNA gene of zebrafish (kindly provided by J.C. Smith, National Institute for Medical Research, London, England) to control for equal recovery and processing.

\section{Acknowledgments}

We thank Drs. S. Schulte-Merker and C. Nüsslein-Volhard for the Brachyury antibody and communication of data before publication, Drs. C. Kimmel and M. Westerfield for wild-type and mutant zebrafish lines, Ian Goldsmith (ICRF) for oligonucleotide synthesis, J. Smith for gifts of activin A and the 5S RNA probe, Drs. E. Oxtoby and T. Jowett for making the zebrafish Krox-20 probe available before publication, and Dr. S. Krauss for the zebrafish pax probes. We are grateful to C. Kimmel, C. Walker, M. Westerfield, and the people of Monte Westerfield's laboratory for their hospitality and the stimulating discussions during the stay of one of us (U.S.) in Eugene. We thank Emma Burns for excellent technical assistance and our colleagues at the Developmental Biology Unit (DBU) for many helpful discussions. U.S. is a Boehringer Ingelheim fellow. This work was supported by the Imperial Cancer Research Fund.

The publication costs of this article were defrayed in part by payment of page charges. This article must therefore be hereby marked "advertisement" in accordance with 18 USC section 1734 solely to indicate this fact.

\section{Note added in proof}

The sequence data described in this paper have been submitted to the EMBL/GenBank data libraries under accession number Z22762.

\section{References}

Bernhardt, R.R., N. Nguyen, and J.Y. Kuwada. 1992. Growth cone guidance by floor plate cells in the spinal cord of the zebrafish embryo. Neuron 8: 869-882.

Bovolenta, P. and J. Dodd. 1991. Perturbations of neuronal differentiation and axon guidance in the spinal cord of mouse embryos lacking a floor plate: Analysis of Danforth's shorttail mutation. Development 113: 625-639.

Calberla, E. 1877. Zur Entwicklung des Medullarrohres und der Chorda dorsalis der Teleostier und der Petromyzonten. Morph. Jb. 13: 226-267.

Chirgwin, J.M., A.E. Przybyla, R.J. MacDonald, and W.J. Rutter. 1979. Isolation of biologically active ribonucleic acid from sources enriched in ribonuclease. Biochemistry 18: 5294-5299.

Cho, K.W., B. Blumberg, H. Steinbeiser, and E.M. De Robertis. 1991. Molecular nature of Spemann's Organizer: The role of the Xenopus homeobox gene goosecoid. Cell 67: 1111-1120.

Clarke, J.D.W., N. Holder, S.R. Soffe, and J. Storm-Mathisen. 1991. Neuroanatomical and functional analyzis of neural tube formation in notochordless Xenopus embryos; laterality of the ventral spinal cord is lost. Development 112: 499516.

De Robertis, E.M., G. Oliver, and C.V.E. Wright. 1989. Determination of axial polarity in the vertebrate embryo: Homeodomain proteins and homogenetic induction. Cell 57: 189191.

Dirksen, M.L. and M. Jamrich. 1992. A novel, activin-inducible, blastopore lip-specific gene of Xenopus laevis contains a fork head DNA-binding domain. Genes \& Dev. 6: 599-608.

Frohman, M.A., M. Boyle, and G.R. Martin. 1990. Isolation of the mouse Hox-2.9 gene; analyzis of embryonic expression suggests that positional information along the anterior-posterior axis is specified by mesoderm. Development 110: 589-607.

Gimlich, R.L. and J.C. Gerhardt. 1984. Early cellular interaction promote embryonic axis formation in Xenopus. Dev. Biol. 104: $117-130$

Godsave, S.F., H.V. Isaacs, and J.M.W. Slack. 1988. Mesoderminducing factors: A small class of molecules. Development 102: $555-566$.

Green, J.B.A. and J.C. Smith. 1991. Growth factors as morphogens: Do gradients and thresholds establish the body plan? Trends. Genet. 7: 245-250.

Häcker, U., U. Grossniklaus, W. Gehring, and H. Jäckle. 1992. Developmentally regulated Drosophila gene family encoding the fork head domain. Proc. Natl. Acad. Sci. 89: 8754 8758.

Hatta, K. 1992. Role of the floor plate in axonal patterning in the zebrafish CNS. Neuron 9: 629-642.

Hatta, K., C.B. Kimmel, R.K. Ho, and C. Walker. 1991. The cyclops mutation blocks specification of the floor plate of the zebrafish central-nervous-system. Nature 350: 339-341.

Ho, R.K. 1992. Axis formation in the embryo of the zebrafish, Brachydanio rerio. Sem. Dev. Biol. 3: 53-64.

Jessel, T.M. and D.A. Melton. 1992. Diffusible factors in vertebrate embryonic induction. Cell 68: 257-270.

Kawasaki, E.S. and A.M. Wang. 1989. Detection of gene expres- 
sion. In PCR technology (ed. H.A. Ehrlich), pp. 89-97. Stockton Press, New York.

Kingsbury, B.F. 1930. The developmental significance of the floor plate of the brain and spinal cord. I. Comp. Neurol. 50: $177-2070$.

Knöchel, S., J. Lef, J. Clement, B. Klocke, S. Hille, M. Köster, and W. Knöchel. 1992. Activin A induced expression of a fork head related gene in posterior chordamesoderm (notochord) of Xenopus laevis. Mech. Dev. 38: 157-165.

Kozak, M. 1986. Point mutations define a sequence flanking the AUG initiator codon that modulates translation by eukaryotic ribosomes. Cell 44: 283-292.

Krauss, S., T. Johansen, V. Khorz, and A. Fjose. 1991a. Expression of the zebrafish paired box gene pax $[z f-b]$ during early neurogenesis. Development 113: 1193-1206.

Krauss, S., T. Johannsen, V. Korzh, U. Moens, J.U. Ericson, and A. Fjose. 1991 b. Zebrafish pax[zf-a $]$; a paired box-containing gene expressed in the neural tube. EMBO $\%$ 10: 3609-3619.

Krauss, S., T. Johansen, V. Korzh, and A. Fjose. 1991c. Expression pattern of zebrafish pax genes suggest a role in early brain regionalization. Nature 353: 267-270.

Lai, E., V.R. Prezioso, E. Smith, O. Litvin, R.H. Costa, and J.E. Darnell. 1990. HNF-3A, a hepatocyte-enriched transcription factor of novel structure is regulated transcriptionally. Genes \& Dev. 4: 1427-1436.

Lai, E., V.R. Prezioso, W. Tao, W.S. Chen, and J.E. Darnell. 1991. Hepatocyte nuclear factor $3 a$ belongs to a gene family in mammals that is homologous to the Drosophila homeotic gene fork head. Genes \& Dev. 5: 416-427.

Long, W.L. 1983. The role of the yolk syncytial layer in determination of the plane of bilateral symmetry in the rainbow trout, Salmo gairdneri Richardson. J. Exp. Zool. 228: 91-97.

Luther, W. 1935. Entwicklungsphysiologische Untersuchungen am Forellenkeim: Die Rolle des Organisationszentrums bei der Entstehung der Embryonalanlagen. Biol. Zentralbl. 55: 114-137.

Mangold, O. 1931. Das Determinationsproblem III. Das Wirbeltierauge in der Entwicklung und Regeneration. Erg. Biol. 7: 193-402.

Mohun, T.J., S. Brennan, N. Dathan, S. Fairman, and J. Gurdon. 1984. Cell-specific activation of actin genes in the early amphibian embryo. Nature 311: 716-721.

Nieto, M.A., L.C. Bradley, and D.G. Wilkinson. 1991. Conserved segmental expression of Krox-20 in the vertebrate hindbrain and its relationship to lineage restriction. Development (Suppl.) 2: 59-62.

Nieuwkoop, P.D. 1973. The "organization centre" of the amphibian embryo; its origin, spatial organization and morphogenic action. Adv. Morphogenet. 10: 2-39.

Oppenheimer, J.M. 1936. Transplantation experiments on developing teleosts (Fundulus and Perca). J. Exp. Zool. 72: 409437.

Oxtoby, E. and T. Jowett. 1993. Cloning of the zebrafish Krox-20 gene $(\mathrm{Krx}-20)$ and its expression during hindbrain development. Nucleic Acids Res. 21: 1087-1095.

Pani, L., D.G. Overdier, A. Porcella, X. Qian, E. Lai, and R.H. Costa. 1992. Hepatocyte nuclear Factor 3b contains two transcriptional activation domains, one of which is novel and conserved with the Drosophila fork head protein. Mol. Cell. Biol. 12: 3723-3732.

Placzek, M., T. Yamada, M. Tessier-Lavigne, T. Jessell, and J. Dodd. 1991. Control of dorsoventral pattern in vertebrate neural development: induction and polarizing properties of the floor plate. Development (Suppl.) 2: 105-122.

Püschel, A.W., M. Westerfield, and G.R. Dressler. 1992a. Comparative analyzis of $\mathrm{Pax}-2$ protein ditributions during neuru- lation in mice and zebrafish. Mech. Dev. 38: 197-208.

Püschel, A.W., P. Gruss, and M. Westerfield. 1992b. Sequence and expression pattern of pax-6 are highly conserved between zebrafish and mice. Development 114: 643-651.

Rosa, F.M. 1989. Mix.1, a homeobox mRNE inducible by mesoderm inducers, is expressed mostly in the presumptive endodermal cells of Xenopus embryos. Cell 57: 965-974.

Ruiz i Altaba, A. and T.M. Jessel. 1992. Pintallavis, a gene expressed in the organizer and midline cells of frog embryos: Involvement in the development of the neural axis. Development 116: 81-93.

Sambrook, J., E.F. Fritsch, and T. Maniatis. 1989. Molecular cloning: A laboratory manual. Cold Spring Harbor Laboratory Press, Cold Spring Harbor, New York.

Schulte-Merker, S., R.K. Ho, B.G. Herrmann, and C. NüssleinVolhard. 1992. The protein product of the zebrafish homologue of the mouse $\mathrm{T}$ gene is expressed in nuclei of the germ ring and the notochord of the early embryo. Development 116: $1021-1032$

Slack, J.M.W. and D. Tannahill. 1992. Mechanism of anteroposterior axis specification in vertebrates, lessons from the amphibians. Development 114: 285-302.

Slack, J.M.W., B.G. Darlington, L.L. Gillespie, S.F. Godsave, H.V. Isaacs, and G.D. Paterno. 1989. The role of fibroblast growth factor in early Xenopus development. Development (Suppl.) 107: 141-148.

Smith, J.C., J. Cooke, J.B.A. Green, G. Howes, and K. Symes. 1989. Inducing factors and the control of mesodermal pattern in Xenopus laevis. Development (Suppl.) 2: 149-159.

Smith, J., B.M.J. Price, J.B.A. Green, D. Weigel, and B.G. Herrmann. 1991. Expression of a Xenopus homolog of Brachyury $(T)$ is an immediate-early response to mesoderm induction. Cell 67: 79-87.

Spemann, H. 1938. Embryonic development and induction. Yale University Press, New Haven, CT.

Spemann, H. and H. Mangold. 1924. Über Induktion von Embryonalanlagen durch Implantation artfremder Organisatoren. Wilhelm Roux's Arch. Entwicklungsmech. 100: 599638.

St. Johnson, D. and C. Nüsslein-Volhard. 1992. The origin of pattern and polarity in the Drosophila embryo. Cell 68: 201219.

Strähle, U., G. Klock, and G. Schütz. 1987. A DNA sequence of 15 base pairs is sufficient to mediate both glucocorticoid and progesterone induction of gene expression. Proc. Natl. Acad. Sci. 84: 7871-7875.

Taira, M., M. Jamrich, P.J. Good, and I.B. Dawid. 1992. The LIM domain-containing homeo box gene $X \lim _{-1} 1$ is expressed specifically in the organizer region of Xenopus gastrula embryos. Genes \& Dev. 6: 356-366.

Tao, W. and E. Lai. 1992. Telencephalon-restricted expression of BF-1, a new member of the HNF3/fork head gene family, in the developing rat brain. Neuron 8: 957-966.

Tautz, D. and C. Pfeifle. 1989. A nonradiactive in situ hybridization method for the localization of specific RNAs in Drosophila embryos reveals a translational control of the segmentation gene hunchback. Chromosomal. 98: 81-85.

Weigel, D. and H. Jäckle. 1990. The fork head domain: A novel DNA-binding motif of eukaryotic transcription factors? Cell 63: 455-456.

Weigel, D., G. Jürgens, F. Küttner, E. Seifert, and H. Jäckle. 1989. The homeotic gene fork head encodes a nuclear protein and is expressed in the terminal regions of the Drosophila embryo. Cell 57: 645-658.

Westerfield, M. 1989. The zebrafish book. University of Oregon Press, Eugene. 




\section{Axial, a zebrafish gene expressed along the developing body axis, shows altered expression in cyclops mutant embryos.}

U Strähle, P Blader, D Henrique, et al.

Genes Dev. 1993, 7:

Access the most recent version at doi:10.1101/gad.7.7b.1436

References This article cites 52 articles, 17 of which can be accessed free at:

http://genesdev.cshlp.org/content/7/7b/1436.full.html\#ref-list-1

License

Email Alerting

Service

Receive free email alerts when new articles cite this article - sign up in the box at the top right corner of the article or click here.

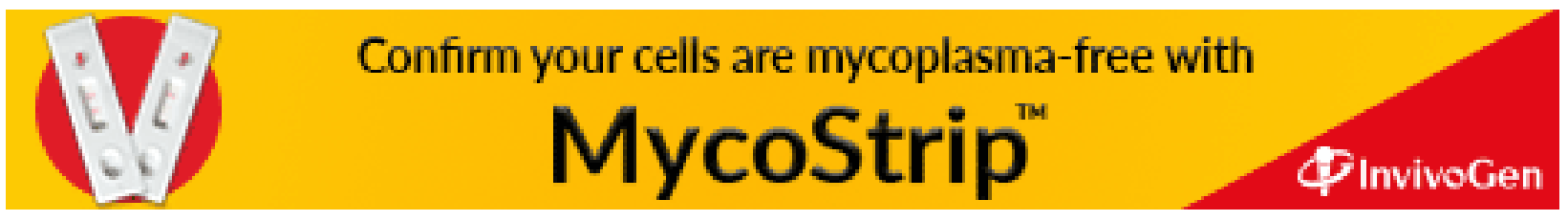

